\title{
Morphophonemic Variation in CaC-Initial Verb Structures in Kuwaiti Arabic
}

\author{
Hanan A. Taqi ${ }^{1}$ \\ ${ }^{1}$ Associate Professor, The English Department, College of Basic Education, Ardhiya, Kuwait \\ Correspondence: Hanan A. Taqi, Associate Professor, The English Department, College of Basic Education, \\ Ardhiya, Kuwait. E-mail: hanan.taqi@gmail.com
}

Received: September 7, 2018 Accepted: November 6, 2018 Online Published: December 27, 2018

doi:10.5539/ijel.v9n1p54 URL: https://doi.org/10.5539/ijel.v9n1p54

\begin{abstract}
This study aims to investigate the linguistic and social factors influencing the realisation of the initial Modern Arabic verb form $\mathrm{CaC}$-in Kuwaiti Arabic (KA). While very few studies have examined the sociolinguistic variation of the initial verb form $\mathrm{CaC}$-in $\mathrm{KA}$, this variable has been found to be produced in the speech of two Kuwaiti communities from different ethnic backgrounds, namely Najdi (from Saudi Arabia originally) and Ajami (from Iran originally). The aim is to analyse the realisation of $\mathrm{CaC}$-forms as a reflection of ethnicity, age and gender in KA. Data were collected from 48 male and female Kuwaiti speakers from two ethnicities (Najdi and Ajami), three age groups (chosen according to relevant milestones in the history of Kuwait). Two main techniques were implemented to collect data in this study, namely spontaneous and controlled data. The investigation showed that there were significant differences in the realisation of the initial verb form $\mathrm{CaC}$-in the two ethnicities and across age and gender. The study also showed that the $\mathrm{CaC}$-form had less prestige than did the CiC-form, which is mostly found in the Najdi variety.
\end{abstract}

Keywords: sociophonetics, Arabic, Kuwaiti, language variation, dialect, accent

\section{Introduction}

Language variation is among the exceptional, essential phenomena that distinguish human social interactions. Dialects occur schematically, and speaking a dialect implies taking on a particular identity associated with that dialect. An element of linguistic variation is that which is found inside a speech network, in which speakers belong to specific age groups, social classes, ethnic groups and/or genders; these factors combine to shape the systematic variations in the manner in which they speak (Coupland, 2007).

Arabic language variation has been of interest to many scholars. Although the study of these different varieties might have been put on hold for years, as such studies were believed to be one of the means of "dialect corruption" (Versteegh, 1997, p. 102), many Arab and European linguists have shown the importance of understanding these variations, as they are a direct reflection of social variables (Abdel-Jawad, 1981; Bakir, 1988; Holes, 1987 \& 2015; Haeri, 1997; among many others).

In the case of the Kuwaiti dialect, history seems to be the main factor affecting the choice of variation. The history of the formation of modern Kuwait goes back more than 500 years, when Bani Utub (from a Saudi Arabian land called Najd) migrated from lands beset by drought and other problems in the Arabian Gulf to the Kuwaiti lands. After the Utubs established themselves economically and socially, their migration was followed by many others from Saudi Arabia, Iraq and Iran. While all migrants to Kuwait spoke a dialect of Arabic, the Farsis that migrated from Iran spoke very little Arabic, and their mother tongue was Persian. These people were called "Ajamis" (meaning "non-Arab").

The language difference between the Ajami and rest of the migrants caused a huge barrier in communication; hence, a significant social distinction was created. The Arabic-and Farsi-speaking communities hardly mingled at first, language being the main reason, although the Ajamis learned Arabic as time passed. The Ajamis and Arabs mingled in schools and at work, and the communities became closer. The status of the Ajamis rose, and it would appear that their command of the language affected their social status. From one generation to the other, the Kuwaiti people from all sectors were heading towards a unified variation (Taqi, 2010).

The following study investigates vocalic variation in the initial verb form CaC-, which affects most present and 
past tense verb derivatives. Unlike the investigation of consonantal variation, the study of vocalic realisation in initial verb forms not only concerns phonological variation, but also morphophonemic alternations. Thus, this investigation addresses the analysis of internal variation determined by differences in verb structure. I will also be discussing sociolinguistic variation, particularly to the social variables of ethnicity, age and gender.

\section{Literature Review}

The investigation of morphological variation in dialects was pioneered by Labov in his 1966 account of the contraction and deletion of the copula in African-American English, in which the deletion occurred in sentences such as "this _ my pen" (Milroy \& Gordon 2003, p. 169). Labov (1966) found the recurrence of the use of a variable feature depended on the circumstances of talking; the / $\mathrm{r} /$ cancellation in New York City could be a clear example of a case in which the sound can be elided after a vowel. Labov found that this cancellation was related to many factors such as social class and the linguistic environment and was influenced heavily by the speaking task. According to Labov, the New York speakers had a tendency to remove $/ \mathrm{r} /$ more frequently when they were telling stories than when they were providing demographic information. Labov noted that the speakers seemed to elide / $\mathrm{r} /$ more often when using an informal style because they paid less attention to how they sounded, and concentrated on telling the story instead. However, in formal situations, the speakers were conscious of their discourse, and attempted to avoid stigmatised forms such as the elided $/ \mathrm{r} /$.

\subsection{Arabic Variation}

Although many studies have investigated the phonological differences found in Arabic dialects, only a few of these have examined morphophonemic variation. In general, Arabic words, regardless of the dialect in which they occur, can be fragmented morphologically into a consonantal skeleton known as the "root". Vowel patterns, however, consist of prefixes and suffixes (affix morphemes) in an intermittent pattern. Thus, changing a vowel prefix could change the tense from present to past. A good example of this is the root of the verb "eat" $/ \mathrm{P} \mathrm{k} 1 /$, which can be transformed into the present /ja?kul/ or past /Pakala/. In 2015, Holes presented an investigation of the differences in verb prefixes and suffixes in the speech of Bahraini Arabs and Baharna, and found variations between these two dialects. One example is the suffix of the second person past plural which, in the Arab dialect, would be [-taw], while in Baharna it would be [-tu:n], as in Arab [katabtaw] (you pl. wrote), which is produced by Baharna speakers as [kitabtu:n] (for Standard Arabic, SA hereafter /katabtu:/) (Holes, 2015, p. 187). The differences found in the Bahraini dialects were mainly due to ethnicity, as the CaCa-past tense verbs were realised differently by Arabs and by Baharna. A good example of this difference is the word [Jaraba] (drank, singular masculine), which is realised by Arabs as [Jarab] and by Baharna as [Jirab].

Another example is the past form pattern that follows the CVCVC-pattern in SA, as in the verb /darasat/ (she studied). Holes (2015) found that, in the Arabic dialect the pattern is CCVCVC [drisat], while the Baharna variety and the urban dialect of Manama follow the SA pattern. In addition, the rural dialects of Bahrain followed the CVCC pattern, as in [dirsat]. Holes (ibid.) also found that the present tense suffixed stem that follows the -CVCC-pattern in SA and Baharna speech follows the -CCVC-pattern in Arab Bahrainis' speech. For example, /talbisi/ (you [feminine, present] wear) is realised by the Arabs as [tlibsi:n] and by the Baharna as [tilbasin]. Age and prestige were shown to correlate with the realisation of this suffixed stem. As the Arabic dialect is considered the most prestigious, the young people of Bahrain from both groups have been shown to use the Arabic pattern more often than they do the Baharna pattern. Holes $(2015$, p. 472) found that age was Strongly correlated with variation, showing evidence taken from age variation from Al-Qouz' 2009 study of the Bahraini dialect. In his study, Al-Qouz found that the second female singular pronoun was being shifted from the traditional [intīn] (you female plural) to [inti/intaj] by the younger generations.

With regard to Bahrain, Holes (1987) described the significance of considering variables; for example, history, geology, ethnic-based gatherings and religion. The Bahrainis are divided into the Sunni and Shi' is, with another division inside the Sunnis between the Hwala and the Arabs who live in towns. The Shi'i division consists of the Baharna - a group that has been living in Manama and small villages. They claim to be the original inhabitants prior to the arrival of the Al-Khalifa family in 1973 (from the Utub branch, related to the Kuwaiti ruling family Al-Sabah-Wilson, 1954, as cited in Holes, 1987, p. 11). The "Ajamis" (Persians) and the Bedouins (Arabs) have inherited virtues of autonomy, masculinity and self-reliance (Holes, 2015, p. 12), and a considerable number of them consider jobs such as offering, selling, barbering, or even tailoring, a disgrace. The prestigious variations of the Arab dialect are mainly adopted by the Baharna together with Standard Arabic (SA) in schools, the media, and social communications, which in turn aided in reducing isolation of these groups (ibid., p. 14). The Shi'i Baharna group embraces the Arab Sunni's dialect publicly, as it represents the dialect of the predominantly powerful and wealthy. Holes (1987, p.17), however, found that when the Arabs were living in the Ajamis' society, 
they did not use the dialect of the Ajamis. Instead, they moved towards the standard variety in order to be understood, regardless of the isolation they felt due to living in a different community. Holes (1987, p. 176) commented on the variation in verb forms by stating that "the morphophonemic variation in BA [Bahraini Arabic] is motivated by consciousness of supradialectal or local prestige forms", adding that although the Baharna pattern in the present tense suffixed stem followed the general pattern found in SA, the verbs showed similarity to the Arab community's pattern. This may indicate an attempt by the Baharna to change their pronunciation to one that was considered to be more prestigious in their community, while also being torn between what is correct and incorrect in SA. This confusion may have led to dialect levelling and to the creation of a new morphophonemic pattern.

Another study on morphophonemic variation was conducted by Al-Wer (2003), who investigated the pronominal suffix -kum [darkum] (your house) in the speech of Amman youngsters. She found that the first generation of inhabitants of Amman did not use this suffix, regardless of whether this generation had originated from Jordan or Palestine. Moreover, -kum does not occur in any Jordanian variety or in any of the urban dialects in the Levant region. In the Palestinian varieties, -kun is suffixed to a verb to indicate the second person plural (for example, [darkun]), which is equivalent to -ku ([darku]) in the Jordanian varieties. In attempt to explain the use of -kum, Al-Wer (2013) stated that "-kum may have become familiar to Ammanis as a legitimate $2^{\text {nd }}$ person plural form through its occurrence as such in the standard variety or in other dialects". Herin and Al-Wer (2013, p. 64) described the variation of -ku in the Salt dialect of Jordan. This suffix was represented in three stages; traditional (no contact with other dialects), intermediate (a little contact with speakers of other dialects) and koineised. Koineisation is a concept that states that the Arabic dialects have experienced a process of levelling, leading to the "uniformization" of the Arabic dialects amongst themselves and with Classical Arabic (Miller, 2007, p. 5). The author found that the younger speakers who had more contact with the Ammani dialect were those who koineised, reflecting the effect of society on dialect shift.

Al-Wer (2003) also believed that -kum was marked phonetically and paradigmatically. It is marked phonetically because gender distinction is preserved in the traditional Jordanian dialects via the use of the front-vowel second person plural suffix -kin (as in [darkin]), while the Palestinian and urban Levantine form -kun has a back vowel. Because the masculine form, not the feminine, is used in Jordanian dialects when gender neutralising and the Palestinian -kun is a feminine form, it is marked paradigmatically. Thus, Al-Wer concluded that the use of -kum by young Ammanis could be an attempt to avoid locally marked forms (in other words, gender distinction). Another explanation for the use of -kum by Ammani youngsters is simplification, whereby a more regular morphophonemic structure is followed. The second plural form underwent a neutralising change in which the form of both masculine and feminine is represented by the masculine -kum [darkin], and [darkun] became [darkum]. Simplification follows the same pattern; thus, the third person plural masculine -hum is generally used for both feminine and masculine suffixes. Finally, Al-Wer reported that dialect mixture between the Jordanian -ku and the Palestinian -kun resulted in the emergence of Ammani -kum. This phenomenon reported by Al-Wer (2013), and the situation in Bahrain reported by Holes (1987), could be a reflection of the morphophonemic situation in Kuwait.

It appears from the cases of Amman and Bahrain that social networks are one of the main factors. Social networks is a notion taken from research conducted by Leslie and James Milroy (1978) and L. Milroy (1987) to portray the use of linguistic features that develop through the interaction of groups of people on a daily basis (see Milroy \& Gordon, 2003). When applying this theory to the situation of Arabic linguistics, social networks, which originate due to financial, political and demographic factors such as social blending encouraged by urbanisation, subsequently prompt linguistic change. More precisely, the "adaptability" of social factors, for example social class and instruction, which encourage linguistic change from the top of the social scale; for instance, a doctor who is considered at the top of the working class would scale the social step and strive higher-class esteem and habits, including dialect (Bassiouney, 2009, p. 124). In addition, the community of practice is another concept associated with social networks. This concept describes unchangeable variables such as ethnicity, religion and tribal belonging. These variables restrain phonetic change; hence, a person whose status is dependent upon his/her tribal group's status or religion cannot change his or her innate alliance or religion. Such unchangeable factors frame the community of practice and protect the shared linguistic features, as in the situation for Palestinians in Lebanon or in Syria. On the other hand, "social networks when loosened by different factors, such as economic or political ones or urbanization when it changes the structure of a community may lead to language change" (Bassiouney, 2009, p. 124).

\subsection{Kuwaiti Arabic}

The varieties of speech are socially classified in Kuwait; Kuwaiti Arabic (KA hereafter) is the spoken language 
of Kuwaitis, and is divided into KA and Bedouin. The Ajamis speak KA, but with a slightly different accent. Other non-Kuwaiti dialects in Kuwait are Palestinian, Syrian, Jordanian and Egyptian. In addition, there are non-Arab languages such as English, Hindi-Urdu, Farsi and Philippine varieties.

Kuwaiti Arabic comprises two main varieties, specifically Modern and Bedouin. As Modern Kuwaiti Arabic (MKA hereafter) was the dialect spoken by the Al-Sabah family and the Najdi families who have migrated with them; their status was set due to the economic and social development. Thomason $(2001$, p. 3$)$ explained this phenomena as a case of language contact that involved "face to face interactions among groups of speakers at least some of whom speak more than one language in a particular geographical locality". People came from all across the peninsula in the situation of MKA, and spoke different varieties of Arabic, Persian and Urdu. Changes in prestige began to occur due to the different backgrounds of the Kuwaiti people and their connections with people from the outside world (especially in Arabic countries such as Lebanon, Egypt, Jordan and Syria). In this regard, Thomason (ibid., p. 3) added that "neighbouring speaker groups may be on friendly terms-sharing resources, engaging in trade, and providing mutual support". Nonetheless, separation of ethnicities and living areas was usually the case in the Kuwaiti context, even in those regions in which each group lived closely together. The status of MKA was a reflection of social and economic power being the variety utilized by the royal family and the merchants that migrated with them. The majority of people who did not belong to these families worked with them or for them, consequently having the chance to adopt their variety (Al-Sab'an, 2002).

After the discovery of oil, a huge development era started, this caused a large amount of people migrating to Kuwait for job opportunities, and Kuwaitis began to travel abroad for education and trade. The persistent contact with speakers of other Arabic dialects and certainly with non-Arabic languages affected KA and encouraged the borrowing of lexemes from different varieties of Arabic (including those from the communities discussed in previous sections), Farsi, Indian and English. It is not surprising, hence, to find that that the first reported dialectal and language changes in certain respects were exhibited in the language of merchants who interacted on daily basis with other Arabs. The Educated community also began to follow in the merchants' footsteps, and major lexical changes occurred as a result. By contrast, Bedouins showed a general preservation of their language because of their lifestyle which depended mainly on constant movement, and thus rarely communicated with other communities, especially outside Kuwait (Al-Anezi, 2006, p. 34).

The first language to be learned by children is MKA. It is the mother tongue of Kuwaiti children, learned first by pre-schoolers and in many instances, this variety is learned even before school, and continues to be learned after. The scenario in Kuwait, thus, is diglossic where KA and MSA occur side by side in the community. The informal language of Kuwait that is used to communicate with friends and co-workers is KA, whereas the formal language used in television programmes, newspapers and news reports is MSA.

In a 1967 language investigation, Johnstone believed the dialects of Kuwaiti were heading towards extinction due to the changes he noted in MKA caused by language contact. In his assumption, Johnstone believed that the Kuwaiti varieties would be replaced by a "pan-Arabic Koine" (xxviii). His views were based on his findings that the Kuwaiti varieties were changing rapidly by wide communication and enhanced educational pursuit. This rapid change, in his point of view, endangered the Kuwaiti dialect. Yet, after five decades of Johnstone's report, the Kuwaiti dialects remain distinctive and thriving. In a more recent study, Holes $(1995$, p. 61) remarked on Johnstone's claims by stating:

His [Johnstone's] pessimism was not justified. The demographic policies adopted by the Kuwaiti government which accompanied the country's rise to economic dominance, and which can be seen as a defence against the dilution of the Kuwait identity by the huge numbers of expatriate Arabs and others who flocked there, were resolutely separatist and non-assimilatory.

When comparing the Kuwaiti dialect to the Bahraini dialect, Holes (1995) also noted that Kuwaitis did not speak to non-Kuwaitis using their own dialectal variety. They usually combined the standard with the recipient's variety and the Kuwaiti variety. The Kuwaiti dialect was merely spoken within the Kuwaiti families and social surroundings. He also noted that the Kuwaiti dialect did not encounter change, but was mainly used between the Kuwaitis. Thus, he concluded that the Kuwaiti dialect has eloquently survived, and it was closely related to a sense of local belonging. Today, the Kuwaiti dialect highly used in television, radio, theatre, soap opera and even in poetry as it is widely understood and accepted in the community. (Taqi, 2010)

\subsection{The Initial CaC-Verb Structure}

The initial structure of verbs that follow the SA CaC-pattern investigated in this study are the present tense verb derivatives; examples of SA verb skeleton, and the changes that are influenced by the addition of vowels and affixed morphemes: 
a) Third person singular masculine and feminine

b) Third person plural (used in KA for both genders)

c) Second person plural (also used in KA for both genders)

d) First person plural (used in KA for both genders)

In addition to the present tense verbs, the following past tense verbs are also explored - all of which (apart from the $3^{\text {rd }}$ person singular masculine) are associated with both genders:
e) First person singular
f) First person plural
g) Second person singular
h) Second person plural
i) Third person singular (masculine only).

In Arabic, regardless of whether being standard or dialect, most verbs can be traced back morphologically to their roots. The root of a verb is considered to be a skeleton (often consonantal). When adding vowels, prefixes and affixes to this skeleton, different verb tenses and persons are produced (Holes, 1987, p. 107). Table 1 below shows examples of SA verb skeleton, and the changes that are influenced by the addition of vowels and affixed morphemes.

Table 1. Two examples of verb change by the addition of vowels and affixes

\begin{tabular}{|c|c|}
\hline Verb skeleton: S m ؟ (to hear) & Verb Skeleton: k t b (to write) \\
\hline Present tense ( $3^{\text {rd }}$ singular feminine) & Present tense $\left(3^{\text {rd }}\right.$ singular feminine $)$ \\
\hline $\mathrm{SA} /$ tasmaS/ & $\mathrm{SA} /$ taktub/ \\
\hline Najdi [tismaY] & Najdi [tiktib] \\
\hline Ajami [tasmaS] & Ajami [taktib] \\
\hline Present tense ( $3^{\text {rd }}$ plural masculine $)$ & Present tense ( $3^{\text {rd }}$ plural masculine $)$ \\
\hline SA/jasmaGu:n/ & SA/jaktubu:n/ \\
\hline Najdi [jismaSu:n] (masc. and fem.) & Najdi [jiktibu:n] (masc. and fem.) \\
\hline Ajami [jasmaSu:n] & Ajami [jaktubu:n] \\
\hline Present tense ( $2^{\text {nd }}$ plural masculine): & Present tense ( $2^{\text {nd }}$ plural masculine): \\
\hline SA/tasmaYu:n/ & SA/taktibu:n/ \\
\hline Najdi [tismaSu:n] (masc. and fem.) & Najdi [tiktibu:n] (masc. and fem.) \\
\hline Ajami [tasmaYu:n] & Ajami [taktibu:n] \\
\hline Present tense ( $\left(1^{\text {st }}\right.$ plural feminine and masculine): & Present tense $\left(1^{\text {st }}\right.$ plural feminine and masculine): \\
\hline $\mathrm{SA} / \mathrm{samiYat} /$ & $\mathrm{SA} /$ katabat/ \\
\hline Najdi [simaSat] & Najdi [kitabat] \\
\hline Ajami [samaSat] & Ajami [katbat] \\
\hline Past tense ( $3^{\text {rd }}$ singular masculine): & Past tense ( $3^{\text {rd }}$ singular masculine): \\
\hline $\mathrm{SA} / \mathrm{samaSa} /$ & $\mathrm{SA} / \mathrm{kataba/}$ \\
\hline Najdi [simaS] & Najdi [kitab] \\
\hline Ajami [samaY] & Ajami $[\mathrm{katab}]$ \\
\hline Past tense (2nd plural masculine): & Past tense ( $2^{\text {nd }}$ plural masculine): \\
\hline $\mathrm{SA} /$ samiGtum/ & $\mathrm{SA} /$ katabtum/ \\
\hline Najdi [simaStaw] (masc. and fem.) & Najdi [kitabtaw] (masc. and fem.) \\
\hline Ajami [samaStaw] & Ajami [katabtaw] \\
\hline Past tense (2nd singular masculine): & Past tense ( $2^{\text {nd }}$ singular masculine): \\
\hline $\mathrm{SA} / \mathrm{samaYat} /$ & $\mathrm{SA} /$ katabat/ \\
\hline Najdi [simaSat] & Najdi [kitabat] \\
\hline Ajami [samaYat] & Ajami $[$ katabat $]$ \\
\hline Past tense ( $1^{\text {st }}$ plural feminine and masculine): & Past tense ( $\left(1^{\text {st }}\right.$ plural feminine and masculine): \\
\hline SA/samiSna/ & SA/katabna/ \\
\hline Najdi [sima@na] & Najdi [kitabna] \\
\hline Ajami [samaSna] & Ajami [katabna] \\
\hline Past tense ( $1^{\text {st }}$ singular feminine and masculine): & Past tense ( $1^{\text {st }}$ singular feminine and masculine): \\
\hline SA/samiSat/ & SA/katabat/ \\
\hline Najdi [simaSat] & Najdi [kitabat] \\
\hline Ajami [samaৎat] & Ajami [katabat] \\
\hline
\end{tabular}


When investigating the difference in the realisation of the verb derivatives chosen, it was found that some verb derivatives were realised similarly by both ethnic groups under the following conditions:

a) When the verb skeleton starts with a glottal stop, it is often omitted in KA. It should be noted that the glottal stop is replaced by [a] in many nouns, as in the word /fa?s/ (axe) that is realised as [fa:s] in KA, and /ma?tam/ (funeral) that is realised in KA as [ma:tam]. However, unlike nouns, verbs in KA that have a glottal stop initially in their root are realised without the first syllable containing the glottal stop. In addition, the verb maintains the $\mathrm{CaC}$-structure. For example, for the root "? $\mathrm{k} \mathrm{l}$ " (to eat), the past tense $3{ }^{\text {rd }}$ singular (masculine in SA)/Rakala/ would be realised by both ethnic groups as [kala/Rakal].

b) When the second consonant in the verb structure is geminate, the verb structure in SA is CaCC-and CuCC-. As the verb structure differs in SA, it also differs in KA. A good illustration of this is the $3^{\text {rd }}$ past tense singular masculine / Yanna/ (sang), which is realised in KA as [Yanna]. In the present tense, the $3^{\text {rd }}$ plural masculine in SA/juYanni:/ would be realised by both groups as [jiYanni:].

These two verb forms listed above were purposely not included in the control data, and very few occurred in the interview data (shown in Table 2 below). Since the two verb forms did not occur frequently in the interview or in the elicited data, both forms were eliminated from the descriptive statistics.

Table 2. Verbs with structures realised similarly by both ethnicities

\begin{tabular}{|c|c|}
\hline Verb structure & Verbs that occurred in the interview data \\
\hline \multirow[t]{2}{*}{ Verb root starts with / $/$} & /Rakala/ (he ate) - [kala] \\
\hline & /Paxaða/ (he took) - [xaða] \\
\hline \multirow[t]{10}{*}{ Second consonant geminate } & /Yanna/ (he sang) - [Yanna] \\
\hline & / Saddal/ (he amended) - [Yaddal $]$ \\
\hline & /radzdzaS/ (he returned) - [radzdzaS] \\
\hline & /samma/ (he named) - [samma] \\
\hline & /sallam/ (he greeted) - [sallam] \\
\hline & /qaddam/ (he introduced) - [qaddam] \\
\hline & /farraY/ (he emptied) - [farraY] \\
\hline & /dzammaS/ (he collected) - [dzammaS] \\
\hline & /rajjah/ (he comforted) - [rajjah] \\
\hline & /sadd/ (he blocked) - [sadd] \\
\hline
\end{tabular}

It was found that Najdis categorically realised this prefix as $\mathrm{CiC}-$, while most Ajamis realised it as $\mathrm{CaC}$. A good example is the verb /samaY/ (he heard), which is realised by Najdis as [simaY] and by Ajamis as [samaY]. However, it was also found that, within the verbs listed above, when a verb root (basic form of a word) starts with a glottal stop (thus following the PVCVC-pattern), both groups realised the verb following the same structure; for example, the verb/Pakal/ (he ate) speech is realised as [kala] in Najdi and Ajami. Another similarity in the speech of both ethnic groups in a CaC-structure occurs when the second consonant is geminate, as in the verb /Gaddal/ (he amended), which is realised by both groups as [Gaddal].

\section{Methodology}

The study was implemented in the State of Kuwait. Among the different dialects of Kuwaiti Arabic, the study focuses on only two, namely, the Najdi dialect (used by Kuwaiti descendants from Najd, an area in Saudi Arabia), and the Ajami dialect (used by Kuwaitis of Iranian descent). The study analyses the differences in the speech of both ethnic groups in the light of three main social factors: ethnicity, age and gender.

The judgment method of sampling was used. The reason for choosing this method was the researcher's need to choose informants that could fit into the specific categories of ethnicity, age and gender. In addition, the "snowball" method, in which one informant would present his/her family to take part in the research, was utilised. This allowed the researcher to access as large a number of participants as necessary within the chosen criteria.

The sample chosen consisted of 48 male and female speakers (24 male and 24 female). Half of the participants were Najdi and half were Ajami. Each group was divided equally into three age categories: 28-32 years of age, 40-50 years of age, and 60-70 years of age. The choices of age groups were essentially linked to certain major historical events. These events moulded the Kuwaiti society known today. The first generation, represented by four informants aged 60 to 70, reflected the generation that lived in Kuwait prior to the economic and social 
development that started after the exploration of oil in the late 1950s. This generation lived mainly in isolation (most Ajamis lived in an area called Sharq, while most Najdis lived in an area called Jibla) (Taqi, 2010). There was hardly any communication between the two communities. The second age group represented the generation that grew up during the economic and social development, and consisted of four informants aged 40 to 50 . The second chosen generation interacted more with other communities due to educational and employment reasons. Although there was still a form of separation, the new lifestyle forced the two ethnicities to communicate more during work and study, that led slightly to friendships being formed. Even with the change of demographic distribution, the new areas consisted of a majority of one of the ethnic groups under study. For example, most Ajamis lived in the new areas of Dasma and Rumaithia, while the areas of Keifan and Khaldiya consisted mainly of Najdi inhabitants. The third generation, on the other hand, consisted of adults aged from 28 to 32 years of age who grew up in an educationally, socially and economically stable era, communicating regularly with all the communities (Taqi, 2010). More areas were inhabited at this time, showing a mixture of Kuwaitis from different ethnic backgrounds. The new generation communicated more with each other, eliminating social differences and creating social networks that were almost impossible for their grandparents. Thus, in every group there were four informants to represent one of the two ethnic groups, a specific age group and gender.

Three methods of recording data were utilised to obtain spontaneous and controlled data that would avoid the limitations of a single method:

- Spontaneous conversation (interview data)

- Picture elicitation and a map (controlled data)

- Researcher-completed questionnaire

The spontaneous conversation recording lasted an average of 20 minutes per informant. A digital recorder was used (Edirol-R) to record the data and transfer them to the computer. Picture elicitation and a map were presented on PowerPoint slides and contained ten verbs that fitted onto two slides. There were also two stories, read by the interviewer, which required the filling of gaps by a derivative of one of the ten verbs, such as "the boy-football", and the gap would be filled with "plays". The pictures were set out in the order in which they occurred in the story. The story was read in the Kuwaiti dialect in different tenses and involved different subjects (gender and number). This activity allowed the recording of the twelve verb derivatives necessary to conduct this study. The use of a fill-in-the-gap technique with the picture elicitation allowed for the spontaneous production of dialectal forms. As much as possible, pictures of local aspects linked to the Kuwaiti social background were used. The informants were required to identify the objects displayed in the slideshow. The mind-map exercise was recorded throughout the session. The use of controlled data allowed the comparison of two sets of identical verbs, thus allowing the researcher to compare the dialects in more detail.

The informants were interview by both the researcher and an assistant for 60-90 minutes. Enable to avoid affecting the speaker's choice of language variety, the Najdi informants were always interviewed by the assist Najdi assistant and the Ajami informants where exclusively interviewed the Ajami assistant. It was important that the researcher was present at all times during interviews to writes notes, and later after the interview, implementing the questionnaire. The researcher selected seven topics to start the interviews. The following topics were specifically chosen as they were found to be very common between Kuwaitis:

- Memories from school and an evaluation of the schooling system in Kuwait.

- The effect of foreign employment on Kuwaiti families in Kuwait.

- Early marriage.

- Humorous frightening and strange childhood memories

- Using foreign languages in Kuwaiti daily communication.

- The role of Kuwaiti women and their rights.

- The constant increase of daily necessities.

In order to examine specific linguistic issues in detail, the researcher administered the questionnaire to gain further incite on socially-related information, such as the participants view point concerning dialectal variation and prestige. Hence, comprehensive evidence was gained by the researcher's follow up associated with the participants' reactions in relation to specific realisations, which a questionnaire alone might not be able to provide. The questionnaire design was adopted from a questionnaire established by Ohannessian, Ferguson and Polome (1975), since was highly comparable to the Kuwaiti sociolinguistic conditions. The questionnaire was composed two parts. In first segment, the informants were asked to give personal information, such as gender, 
age, and level of education. The second segment entailed the varieties spoken in Kuwait and the environment where Kuwaitis used these varieties.

All the data collected were analysed using SPSS. Because the data are presented according to a scale (percentages of $\mathrm{N}$ ) and are thus equal, an ANOVA test was found to be appropriate for this study. The use of ANOVA test technique yields F-statistics, which in turn are useful in calculating the p-value. The null hypothesis is rejected if $p<0.05$, which will display the assumption that the average of the dependent variable is different between the independent variable groups (Griffith, 2007). To be able to compare the morphophonological realisations to one or more independent variable, one-, two-and three-way ANOVAs tests were conducted.

\section{Results and Discussion}

The variation found in the CaC-initial verb structure under investigation was found in the Ajami group only, and Najdis categorically realised these verb forms as CiC-. Although this confirms that the realisation of the verb structure correlates with ethnic backgrounds, the statistical description of the Ajami versus the Najdi realisation on its own is not informative. Therefore, this section will focus on the analysis of gender and age as social factors influencing the realisation of the $\mathrm{CaC}$-initial verb structure, and will only refer to ethnicity when necessary.

\subsection{Data and Statistics for the CaC-initial Verb Structure}

Figure 1 represents both controlled and interview data. The total number of tokens from the controlled data is 4320 (90 tokens per speaker). On the other hand, the total number of tokens collected in the interview data is 1968 (an average of 41 tokens per speaker). The verb derivatives varied in their total number of occurrences in the interview data, as $62 \%$ of the tokens in the interview data were in the present tense third person singular. However, as their initial verb structure followed the CaC-pattern in SA, they were all considered to form one group. Figure 1 below displays the use of CaC-, where the missing percentages reflect the use of CiC-. The Najdi group was naturally not included here as it categorically used the CiC-verb prefix pattern. The figure encompasses all such data for the Ajami informants, grouped according to gender and age. Where possible, analyses will consider data from both controlled and interview data. The two-way multi factorial ANOVA (age by gender) was calculated for the mean of CaC-verb structure use values. Table 3 below shows the significance of the social factors independently and when interacting with each other in the realisation of $\mathrm{CaC}$-initial verb forms as CaC-. In this way, each social variable can be investigated separately and when interacting with other social variables.

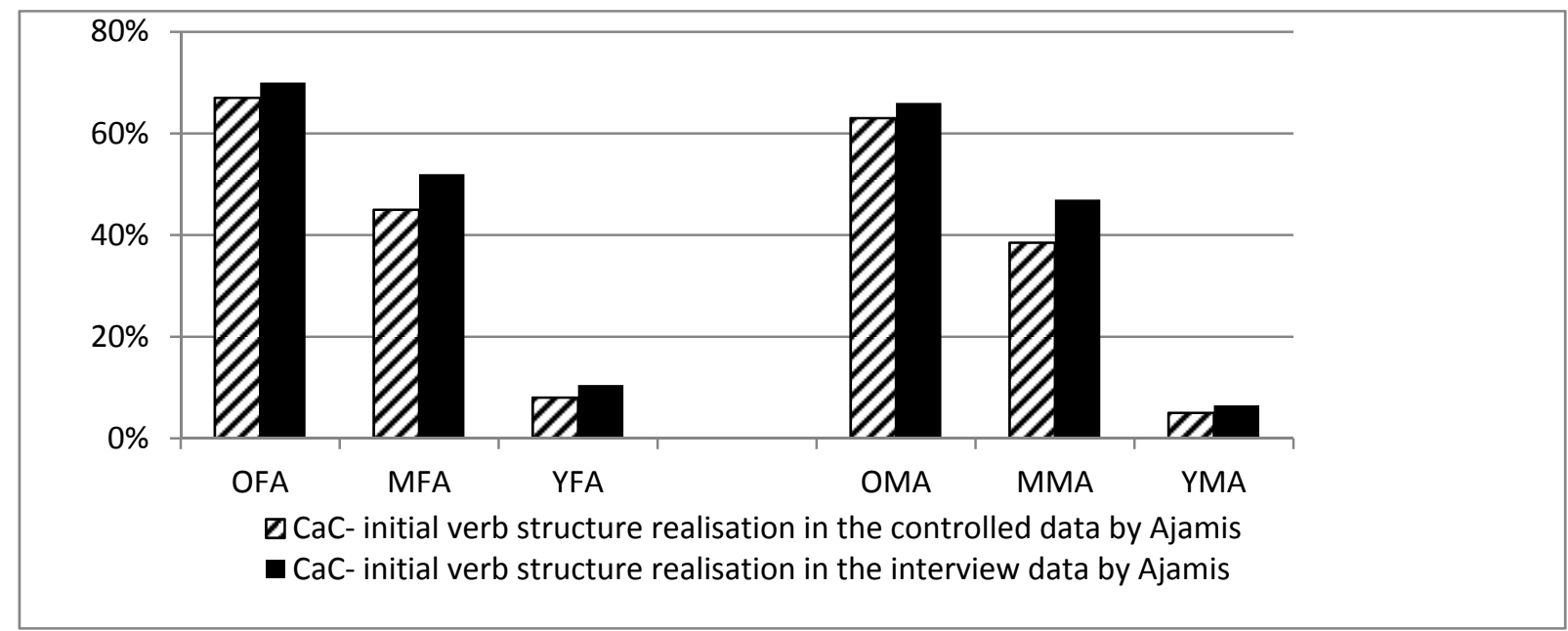

Figure 1. The CaC-realisation in both data sets from the Ajami group*

*the missing percentages are of the $\mathrm{CiC}$-verb prefix realisation (excluding glottal stop initial and geminates). 
Table 3. Significance of social variables in the realisation of CaC-verb structure by Ajamis

\begin{tabular}{|c|c|c|c|c|c|c|}
\hline Source & Dependent Variable & Type III Sum of Squares & df & Mean Square & $\mathrm{F}$ & Sig. \\
\hline \multirow[t]{2}{*}{ Corrected Model } & controlled data & $14947.333(\mathrm{a})$ & 5 & 2989.467 & 75.154 & .000 \\
\hline & interview data & $16908.833(b)$ & 5 & 3381.767 & 966.219 & .000 \\
\hline \multirow[t]{2}{*}{ Intercept } & controlled data & 38720.667 & 1 & 38720.667 & 973.425 & .000 \\
\hline & interview data & 9520.167 & 1 & 9520.167 & 2720.048 & .000 \\
\hline \multirow[t]{2}{*}{ Gender } & controlled data & 150.000 & 1 & 150.000 & .187 & .670 \\
\hline & interview data & 9520.167 & 1 & 9520.167 & .166 & .687 \\
\hline \multirow[t]{2}{*}{ Age } & controlled data & 14625.333 & 2 & 7312.667 & 271.164 & .000 \\
\hline & interview data & 3694.333 & 2 & 1847.167 & 811.344 & .000 \\
\hline \multirow[t]{2}{*}{ Gender* age } & controlled data & 172.000 & 2 & 86.000 & 0.290 & .751 \\
\hline & interview data & 3694.333 & 2 & 1847.167 & 0.154 & .859 \\
\hline \multirow[t]{2}{*}{ Error } & controlled data & 716.000 & 18 & 39.778 & & \\
\hline & interview data & 63.000 & 18 & 3.500 & & \\
\hline \multirow[t]{2}{*}{ Total } & controlled data & 54384.000 & 24 & & & \\
\hline & interview data & 26492.000 & 24 & & & \\
\hline \multirow[t]{2}{*}{ Corrected Total } & controlled data & 15663.333 & 23 & & & \\
\hline & interview data & 16971.833 & 23 & & & \\
\hline
\end{tabular}

\subsubsection{Cac-Verb Structure Realisation by Age}

Age has shown to be a highly influential factor in the realisation of $\mathrm{CaC}$-initial verb forms. Hence, in Figure 1, there is a sharp drop in the use of $\mathrm{CaC}$-verb structures across age groups. The young speakers showed the least use of $\mathrm{CaC}$-verb forms, while the oldest group used $\mathrm{CaC}$-most often. A one-way analysis of the effect of age on the values of $\mathrm{CaC}$-realisation by the Ajamis showed that $\mathrm{F}(2.23)=271.164, \mathrm{p}<0.01$ in the controlled data, and $\mathrm{F}(2.23)=811.344, \mathrm{p}<0.01$ in the interview data. Table 4 shows the percentages of $\mathrm{CaC}$-use in the Ajami group by age in both datasets. The data reflect that the Najdi realisation was used most frequently by the youngest group.

Table 4. The use of $\mathrm{CaC}$-initial verb structure

\begin{tabular}{lll}
\hline Age group & Controlled data & Interview data \\
\hline Old & $65 \%$ & $68 \%$ \\
Middle-aged & $42 \%$ & $49.5 \%$ \\
Young & $6.5 \%$ & $9 \%$ \\
\hline
\end{tabular}

\subsubsection{Cac-Verb Structure Realisation by Gender}

Gender does not play as active a role in the use of $\mathrm{CaC}$-verb forms as age appears to do, which is similar to the results found in [d] ] use. Although female speakers showed a greater use of the $\mathrm{CaC}$-verb structure, the one-way ANOVA results for gender use of $\mathrm{CaC}$-form in the Ajami group showed that $\mathrm{F}(1.23)=0.187, \mathrm{p}=0.670$ in the controlled data and $\mathrm{F}(1.23)=0.166, \mathrm{p}=0.687$ in the interview data, where $\mathrm{p}=0.05$. Table 5 below shows the percentage of $\mathrm{CaC}$-initial verb structure use in the speech of male and female Ajamis. The data reflect that the Najdi realisation was used infrequently by the youngest group.

Does gender correlate with $\mathrm{CaC}$-initial verb structure? Male speakers have been shown to use $\mathrm{CaC}$-less often than female speakers do in general as far as the quantitative analysis is concerned. In every age group, male speakers used $\mathrm{CaC}$-less often. Although the gender difference is insignificant in general in the use of CaC-forms, when gender interacts with age, this shows a significant correlation with the use of $\mathrm{CaC}$-in the old and middle-aged groups.

Table 5. Use of CaC-verb structure by gender in the Ajami group

\begin{tabular}{lll}
\hline Gender & Controlled data & Interview data \\
\hline Male & $40 \%$ & $44.4 \%$ \\
Female & $456.5 \%$ & $49 \%$ \\
\hline
\end{tabular}


When age interacts with gender, a two-way ANOVA (gender by age) result for the use of the CaC-initial verb structure in Ajami speech showed $F(4.23)=0.290, p=0.751$ in the controlled data, and $F(4.23)=0.154, p=0.859$ in the interview data. As age has been shown to be a significant factor affecting the use of CaC-verb forms, a further analysis of age and gender interaction was required. By dividing the age groups and conducting a one-way ANOVA by gender, as in Table 6, it would seem that gender is only a significant factor in determining variation for speakers who are either old or middle-aged.

Table 6. Significance of age by gender in the use of the $\mathrm{CaC}$-verb form in the speech of Ajamis

Old Ajamis

\begin{tabular}{|c|c|c|c|c|c|c|}
\hline & & $\begin{array}{l}\text { Sum of } \\
\text { Squares }\end{array}$ & $\mathrm{df}$ & Mean Square & $\mathrm{F}$ & Sig. \\
\hline \multirow[t]{3}{*}{ Controlled data } & Between Groups & 32.000 & 1 & 32.000 & 12.263 & .037 \\
\hline & Within Groups & 152.000 & 6 & 25.333 & & \\
\hline & Total & 184.000 & 7 & & & \\
\hline \multirow[t]{3}{*}{ Interview data } & Between Groups & 32.000 & 1 & 32.000 & 22.000 & .012 \\
\hline & Within Groups & 4.000 & 6 & .667 & & \\
\hline & Total & 36.000 & 7 & & & \\
\hline
\end{tabular}

Middle-aged Ajamis

\begin{tabular}{|c|c|c|c|c|c|c|}
\hline & & $\begin{array}{l}\text { Sum of } \\
\text { Squares }\end{array}$ & $\mathrm{df}$ & Mean Square & $\mathrm{F}$ & Sig. \\
\hline \multirow[t]{3}{*}{ Controlled data } & Between Groups & 84.500 & 1 & 84.500 & 10.787 & .017 \\
\hline & Within Groups & 47.000 & 6 & 7.833 & & \\
\hline & Total & 131.500 & 7 & & & \\
\hline \multirow[t]{3}{*}{ Interview data } & Between Groups & 50.000 & 1 & 50.000 & 75.000 & .000 \\
\hline & Within Groups & 4.000 & 6 & .667 & & \\
\hline & Total & 54.000 & 7 & & & \\
\hline
\end{tabular}

Young Ajamis

\begin{tabular}{|c|c|c|c|c|c|c|}
\hline & & $\begin{array}{l}\text { Sum of } \\
\text { Squares }\end{array}$ & df & Mean Square & $\mathrm{F}$ & Sig. \\
\hline \multirow[t]{3}{*}{ Controlled data } & Between Groups & 18.000 & 1 & 18.000 & .529 & .494 \\
\hline & Within Groups & 204.000 & 6 & 34.000 & & \\
\hline & Total & 222.000 & 7 & & & \\
\hline \multirow[t]{3}{*}{ Interview data } & Between Groups & 32.000 & 1 & 32.000 & 2.743 & .149 \\
\hline & Within Groups & 70.000 & 6 & 11.667 & & \\
\hline & Total & 102.000 & 7 & & & \\
\hline
\end{tabular}

The young male group showed the least use of $\mathrm{CaC}-(5 \%$ in the controlled data, and $6.5 \%$ in the interview data). The old female Ajami group showed the most frequent use of the CaC-verb form variant. The male Ajamis' pattern was close to that of females in their use of the $\mathrm{CiC}$-initial verb structure, which is the form used by Najdis.

\subsubsection{Discussion of the Social Significance of Cac-Verb Structure Realisation}

This study has shown that, in the Gulf communities, the "standard" and "prestige" are not always parallel. The dialect of the Najdi group has shown to be of high prestige, as Najdis are known to be economically and socially powerful in the Kuwaiti society. The change that occurred in the Kuwaiti dialect in this study has clearly tended towards the Najdi dialect. The Ajami dialect was very similar to SA, as [samaYadz] (heard) in SA is realised as [samaS] by Ajamis, but was realised as [simaY] by Najdis. Many studies have researched the status of SA and the vernacular of Arabic (Ibrahim, 1986; Abu-Haider, 1989; Abdel Jawad, 1981; among others). Most of these studies seem to relate to the Kuwaiti dialect situation. For example, Ibrahim (1986) noted that SA has a high degree of prestige because it is linked to religion and education. However, stronger connotations are indicated by the local vernacular, as the vernacular is an indication of socio-economic class, and is therefore more important to individuals. In Kuwait, the local verb prefix [CiC-] appears to be more prestigious than does SA [CaC-]. The choice of the Najdi variant seems to be due to the fact that the Najdis have a socio-economically prestigious 
status in Kuwaiti. This finding concurs with Bakir's $(1986$, p. 6) finding that, "in Arabic countries, local urban dialects are considered parallel to the standard form if not more prestigious". Even though most participants believed both variants were equal, and that the use of either was not stigmatised, the Ajamis are starting to shift towards the Najdi variants.

The results above appear to be influenced by prestige; as Mazraani $(1997$, p. 7) stated, "the dialect which has great prestige and that is recognized as a hallmark of local identity and pride in the community" is used more widely in the community. Prestige, as identified by Sidnell (1999, p. 394), is determined by a code of power and the speakers' desire to be identified as belonging to a certain community or group. This identifies the insistence of many Ajamis on using the Najdi variant, as it reflects a straightforward connection with social class and economic power (see the literature review for further comments about economic power). An example of power was shown previously by Taqi (2010), where the local variant [j] appeared to be more prestigious than was [d]]. The study showed that the local Najdi variant was being used more frequently, even by the Najdis themselves. The findings of this investigation also coincide with Holes' (1987, p. 104) findings regarding the dialects of Bahrain, where the less prestigious variant "Baharana" was similar to SA, yet the people using the variant tended to change it towards the local Arab variant, as it was considered more prestigious than SA in many cases. A good example provided by Holes (ibid.) was the avoidance of the use of the Baharana CaC-verb form by the Arab Bahrainis, as it indicated less prestige. Holes (1987, p. 104) concluded that "the high-status social group shows a much stronger consistent tendency to stick to its dialectal variants than the low status group".

The CaC-verb structure is the form used by many Ajamis; it is also the one used by the Baharna in Bahrain (Holes 2015) and by the Ajamis in Qatar (Al-Amadidhi 1985), all of whom are originally from Iran. The Arabs in these studies, as noted previously, are all originally from Saudi Arabia, and their dialect is known for the re-syllabification of the $\mathrm{CaC}$-initial verb structure to $\mathrm{CiC}$-. However, in Bahrain and Qatar, Arabic speakers sometimes use the $\mathrm{CaC}$-forms, unlike the Najdis in Kuwait, who use the CiC-forms categorically. Holes (2015) stated that the use of CaC-verb forms was found in the speech of some literate Arab Bahrainis, but not in the speech of those who were uneducated (Barharna villagers). He concluded that the use of the CaC-verb structure was due to the knowledge acquired via education, since this form is SA and is thus more formal. Nonetheless, he added that $\mathrm{CaC}$-forms were clearly avoided because they were considered to be distinctly Baharna and thus less prestigious.

Therefore, it is possible that, as Ajamis' first source of Arabic input was reciting versus of the Quran, they adapted the verb structure of SA, which is the use of the $\mathrm{CaC}$-verb form.

The roots of the use of CiC-form by Najdis as opposed to the CaC-initial verb forms are unknown. When the Najdis were asked how the realisation of a verb such as /samaYa/ (he heard) became [simaY] in Najdi speech, none of the 24 Najdis knew. When the Najdis were asked if their parents and grandparents used to say [samaY] or [simaY], they all stated that the CiC-initial verb form was used by every person in the family. One old male Najdi commented that "we read the Quran and know it's not fusha (SA), but my father and uncles say [jismaY] (he listens); of course I'll say the same". While the Najdis definitely considered the CiC-structure to be the Kuwaiti verb structure, $\mathrm{CaC}$-was not considered non-Kuwaiti. When asked what $\mathrm{CaC}$-verb form reflected, fifteen of the twenty-four Najdis believed that many people in the Gulf and Kuwait used it and that it was not particularly different from the CiC-verb form. As one middle-aged female Najdi commented, "I don't think it's important at all. I know many people from different origins, they say [samaY] (he heard), and I think they are speaking fusha." Another middle-aged female stated that she had many friends of Iraqi origin, and believed that they were the only Kuwaitis who used the CaC-verb structure; did she believe it was not Kuwaiti? "No, not at all. It's just more fusha that's all," she replied. Nine of the twenty-four Najdis (three old, four middle-aged and two young) believed that the $\mathrm{CaC}$-verb form reflected either educational or religious influences. They did not believe that origin affected the $\mathrm{CaC}$ - realisation. One young female Najdi stated, "I think people use it in the university in lectures, to sound serious." The last question the Najdis were asked was whether they used a CaC-verb structure at all when they presumably heard it everywhere because it is the SA form. Did they think that they might, in fact, use CaC-form on some occasions? One young male Najdi replied, "It's not weird or wrong, but we're not used to it, and I may say [samaY] (he heard) one day, I don't think it's important." Many Najdis believed that CaC-did not distinguish Kuwaitis from non-Kuwaitis, as it is a structure used in other Gulf countries, along with the $\mathrm{CiC}$-verb form, yet seventeen of the twenty-four Najdi speakers believed that they would try not to use $\mathrm{CaC}$-even though it is $\mathrm{SA}$, is taught in schools, and is used in formal lectures and speeches. One middle-aged female Najdi commented, "It sometimes does not depend on the word sounding Kuwaiti or not, I think [simaS] (he heard) sounds better". One middle-aged male Najdi added, "I think Kuwaitis will always say [simaY] because it's easier, I feel like I need to think before I say [sama9]". 
The interaction of the three sociolinguistic variables of age, ethnicity and gender were investigated in correlation to analyse the use of certain Kuwaiti dialects. Ethnicity, as shown previously, was the dominant factor affecting the choice of morphophonemic variants as it was linked to prestige. Trudgill $(2000$, p. 45) stated that, in several countries such as Canada and Ghana, "different ethnic groups [...] maintain their separateness and identity as much through language as anything else". This "separateness" is reflected in the choice of different languages, and it is also reflected in the choice of different varieties of one language. While this supports the findings of the present study regarding the oldest generations of the Najdi and Ajami ethnic groups, the choice of speaking a certain variety of Kuwaiti was determined by social factors. As Mazraani $(1997$, p. 7) stated, "The dialect which has great prestige and that is recognised as a hallmark of local identity and pride in the community" often determines the speaker's choice. Sidnell $(1999$, p. 394) found that speakers chose a certain variety because of the code of power and the speaker's desire to be identified as being part of a group and associated with that group's identity.

While the first generation seemed to live in isolation (Najdis lived in the area of Jibla and Ajamis lived in an area called Sharq), the second generation mingled with all ethnicities for purposes of work and education, and the third generations lived closer to Kuwaitis of all ethnicities, as the areas have changed and mixed ethnicities live closer together. In this regard, Chambers $(1995$, p. 125) found that the "most isolated speakers tend to be the most consistent dialect speakers". Thus, a person will maintain a certain variety of a language when living in a "small, tightly-knit, close-network type of community" (Trudgill, 1996, p. 3). Eckert (1989, p. 184) claimed that the appearance of vast linguistic changes was created by networks of communication. The interaction of the active members of a society initiate change due to the occurrence of job opportunities and "residential patterns". Labov $(1979$, p. 17) found that the "linguistic situation is bound to be affected by changes in job opportunities and residential patterns". The oldest group of Ajamis was found to use the SA variant [CaC-] more frequently than any other age groups did. The reason for the use of $\mathrm{CaC}$-might be due to the fact that the oldest Ajamis were the children of the first generation of Ajamis who came to Kuwait speaking only Farsi; for religious purposes, they learned to speak SA. This clearly affected their choice of dialect. The younger the age group, the more often the use of the Najdi variant CiC-was found. Similarly, Holes (1987, p. 104) found that, while the less prestigious Bahraini group (Baharna) used SA, it managed to switch to the prestigious dialect of the Arabs in most situations. Therefore, the Baharana used the Arab CiC-verb form. As Blom and Gumperz (1978, p. 417) found, for the third generation, friendship and social life were the "spheres" in which a dialect was moulded. This finding coincides with the findings in the current study and the choice of dialect by the third generation.

Although gender alone was not found to be significant in this study, the statistics showed that women used the $\mathrm{CaC}$-form slightly more often than men did. This finding supports Romaine's $(1994$, p. 99) argument that "one of the sociolinguistic patterns established by quantitative research on urban dialects was that women, regardless of other social characteristics such as class, age, etc., use more standard forms of language than men". Since CaC-is similar to SA, it is expected that women would use CaC-more often. Moreover, Labov (2001:291) believed that women are highly sensitive to stigma and mockery, more so than are men; hence, they would avoid using stigmatised words. However, in this study, $\mathrm{CaC}$-was not the object of stigma, which may be due to its similarity to the SA realisation. As gender's association with language variation choice is vague (since it is closely related to culture and the roles of the genders in a society) (Labov, 1984, p. 304), it appears that, in the Kuwaiti context, when a variable is not stigmatised and is closer to the SA variable, women tend to use it more frequently than men do.

The Najdis agreed that the realisation of the CaC-initial verb structure did not signify Kuwaiti origins; however, not all Ajamis agreed. When asked whether/samaSa/ would be realised as [samaY] or [simaY], seven out of eight of the older age group Ajamis believed both were Kuwaiti forms. Only one old male Ajami joked, "I can't say [samaY] then people will think I'm not Kuwaiti". The middle-aged and young Ajamis all believed that the $\mathrm{CaC}$-initial verb structure should be realised as $\mathrm{CiC}$-in Kuwaiti speech. When asked why they would use it since $\mathrm{CaC}$-is not Kuwaiti, most of them replied that they had tried to change the $\mathrm{CaC}$-verb structure to CiC-, but "it's not as easy". One young male Ajami said, "It's easy to say [samaY], everybody at home says it, a lot of people in diwanya (men's gathering places for socializing) say it, and so it's difficult not to say it from time to time". One young female Ajami asked the researcher, "Did I say [samą], really? I thought I didn't". Her sister added, "It's not always clear, but I like [simaY] more, and try never to say [samaC]". All the young Ajamis believed that CiC-was the "correct" Kuwaiti form, and that $\mathrm{CaC}$-was the Ajami realisation. As a young male Ajami commented, "[simaY] is really Kuwaiti, anything else is not".

In terms of age and gender, it was found that Najdis and the old Ajami group did not believe that the use of $\mathrm{CaC}$-verb forms was stigmatised. They may, however, relate it to religious and educational factors. On the other 
hand, middle-aged and young Ajamis believed that ethnicity correlated with the realisation of CaC-verb forms. More males than female speakers preferred the CiC-verb structure to $\mathrm{CaC}$ -

\section{Conclusion}

This study investigated the sociolinguistic variation in the speech of Najdi and Ajami Kuwaitis. The investigation included the initial verb structure $\mathrm{CaC}$-, which is realised as CiC-by all Najdis and as CaC-by many Ajamis. It was found that the CaC-SA verb form under study has shifted towards the variants of one ethnic community, namely the Najdi. The effect of the social variables ethnicity, age and gender on the realisation of the $\mathrm{CaC}$-initial verb form, and the effect of these social variables when interacting in one-, two-and three-way ANOVAs have been analysed and were found to be significant in many instances.

Ethnicity was shown to be the most significant social variable that affected the realisation of the $\mathrm{CaC}$-initial form. The reason for this clear effect is the role prestige and social status play in the Kuwaiti society. As the Najdis have the highest position on the social scale, they reflect a constant tendency to preserve the Najdi accent under investigation; on the other hand, the Ajamis seem to have the lowest position on the social scale, and thus showed a tendency to drop their accent variants in favour of the Najdi ones (see Holes, 2015).

It was also found that age was a significant social factor affecting the realisation of the $\mathrm{CaC}$-initial verb form. Social network and age have shown to be closely linked. The social and economic growth of Kuwait has shown a straightforward effect on the social network of Kuwaiti Ajamis. As the old Ajamis maintained a close-knit network that was generally based on kin and neighbour relationships, they maintained most of their accent differences. However, although the middle-aged Ajamis also maintained family ties, they also had more contact with other groups in the society, and thus gradually changed their dialect. On the other hand, the young group had experienced wider integration with the broader society, and a weaker association with kin and neighbours. This has affected their dialect and indicates a strong tendency towards dialect levelling (see Trudgill, 1986).

Historic and economic factors have caused the Najdis to believe that their dialect, although different from Modern Arabic, is the "real" Kuwaiti dialect. These factors seemed to have played a major role in pushing the Ajamis towards the adoption of the Najdi variant. Through the investigation of the different age groups, the study also showed that the Ajami accent has gradually changed to sound more similar to the Najdi accent. This fact was reflected when it was found that the youngest group was the group that used the Najdi variant most often. The young Ajamis believed that their accent was exactly like that of their Najdi friends and peers, which reflected their belief that their accent was definitely the "real" Kuwaiti accent.

Gender was also found to be an influential social variable in this study. Although female participants were generally able to identify Najdi variants as opposed to those that were Ajami, their male counterparts seemed to reflect a more conscious view of the Kuwaiti dialect with regard to the use of the CiC-initial verb form. The male Ajamis used the Najdi form CiC-initial verb form instead of the Ajami CaC-verb form more often than did the female Ajamis. However, it was found that the Najdi community did not ridicule the use of the CaC-verb form, which may indicate the reason that female Ajamis showed a slight increase in the use of the CaC-verb forms. Nonetheless, the decrease in the use of the Ajami variant was apparent when analysed statistically when gender was correlated with age groups. When comparing one age group to another, it was found that the Ajami variants decreased more in the speech of male Ajamis than they did in the speech of their female counterpart. This might be due to the increasing demand on the part of male Ajamis to acquire local societal norms and to become submerged in an all-Kuwaiti community.

Many Kuwaitis who participated in this study, particularly Najdi Kuwaitis, openly discussed their belief that dialectal differences are reflections of a person's ethnic, and sometimes religious belonging. It is this belief that has encouraged most Najdis to "correct" their children's use of non-Najdi variants when possible. This belief has also encouraged the young Ajamis to attempt to "correct" a relative or friend in order for his or her pronunciation to shift towards the prestigious Najdi dialect. Although Najdis and Ajamis live and work side by side, this study has shown that dialectal differences are in fact a distance-keeper between the two groups. The language barrier between the two communities has almost disappeared, as Ajamis hardly speak any Farsi and their Kuwaiti Arabic is very similar to that of the Najdis. However, this study has shown that the young Ajamis are still aware of the dialectal differences and are trying their best to eliminate the dialectal differences to avoid social connotations.

\section{References}

Abdel Jawad, H. (1981). Lexical and Phonological Variation in Spoken Arabic in Amman. PhD thesis. University of Pennsylvania.

Abu-Haider, F. (1989). Are Iraqi women more prestige conscious than men? Sex differentiation in Baghdadi 
Arabic. Language in Society, 18, 471-481. https://doi.org/10.1017/S0047404500013865

Al-Amadidhi, D. (1985). Lexical and Sociolinguistic Variation in Qatari Arabic. PhD thesis. University of Edinburgh.

Alanezi, A. A. M. (2006). An Introduction to Kuwait's Modern History. Kuwait: Quran Centre for Historical Studies.

Al-Saban, L. (2002). The Development of the Kuwaiti Dialect (2nd ed.). Kuwait: That Al-Salasil Publishing.

Al-Wer, E. (2003). Education new dialect formation: The focusing of -kum in Amman. In D. Britain \& J. Cheshire (Eds.), Social Dialectology (pp. 59-67). Amsterdam: J. Benjamins. https://doi.org/10.1075/impact.16.06alw

Bakir, M. (1986). Sex differences in the approximation to Standard Arabic: A Case Study. Anthropological Linguistics, 28(1), 3-9.

Bakir, M. (1988). Notes on subjacency as a syntactic constraint in Arabic and English. Papers and Studies in Contrastive Linguistics, 22, 73-96.

Bassiouney, R. (2009). Arabic Sociolinguistics. Edinburgh: Edinburgh University Press. https://doi.org/10.3366/edinburgh/9780748623730.001.0001

Blom, J. P., \& Gumperz, J. J. (1978). Social meaning in linguistic structures: Code-switching in Norway. In J. Gumperz \& D. Hymes (Eds.), Directions in Sociolinguistics (pp. 407-34). New York: Holt, Rinehart \& Winston.

Chambers, J. (1995). Sociolinguistic Theory. Oxford: Blackwell.

Coupland, N. (2007). Style: Language Variation and Identity. UK: Cambridge University Press. https://doi.org/10.1017/CBO9780511755064

Eckert, P. (1989). Jocks and Burnouts: Social Identity in the High School. New York: Teachers College Press.

Griffith, A. (2007). SPSS for Dummies. Wiley Publishing, Inc.

Haeri, N. (1997). The Sociolinguistic Market of Cairo: Gender, Class and Education. London and New York: Kegan Paul International.

Herin, B., \& Al-Wer, E. (2013). From phonological variation to grammatical change: Depalatalisation of /č/ in Salti (E), Ingham of Arabia: A collection of articles presented as a tribute to the career of Bruce Ingham (pp. 55-73). Leiden: Brill.

Holes, C. (1987). Language Variation and Change in a Modernising Arab State: The case of Bahrain. London and New York: Kegan Paul International.

Holes, C. (1995). Modern Arabic: Structures, Functions and Varieties. London: Longman Linguistics Library.

Holes, C. (2015). Dialect, Culture and Society in Eastern Arabia. Volume III: Phonology, Morphology, Syntax, Style. Leiden: Brill.

Ibrahim, M. (1986). Standard and prestigious language: A problem in Arabic sociolinguistics, Anthropological Linguistics, 28, 115-126.

Johnstone, T. M. (1967). Eastern Arabic Dialect Studies. Oxford: Oxford University Press.

Labov, W. (1966). The Social Stratification of English in New York City. Washington DC: Center for Applied Linguistics.

Labov, W. (1984). Research methods of the project on linguistic change and variation. In J. Baugh \& J. Sherzer (Eds.), Language in Use: Readings in Sociolinguistics. Englewood Cliffs: Prentice Hall.

Labov, W. (2001). Principles of Linguistic Change. Oxford: Blackwell.

Labov, W. (Ed.). (1979). Locating Language in Time and Space. New York: Academic Press.

Mazraani, N. (1997). Aspects of Language Variation in Arabic Political Speech-Making. Surrey: Curzon Press.

Miller, C. (2007). Arabic urban vernaculars. Development and change. In C. Miller, E. Al-Wer, D. Caubet, \& J. C. E. Watson (Eds.), Arabic in the City. Issues in Dialect Contact and Language Variation (pp. 1-31). London and New York, Routledge. https://doi.org/10.4324/9780203933367

Milroy, J., \& Milroy, L. (1978). Belfast: change and variation in an urban vernacular. In P. Trudgill (Ed.), Sociolinguistic patterns in British English (vol. 9, no. 1, pp. 43-70). Cambridge University Press. 
Milroy, L. (1987). Language and Social Networks (2nd ed.). Oxford: Basil Blackwell.

Milroy, L., \& Gordon, M. (2003). Sociolinguistics: Method and Interpretation. Malden, MA: Blackwell. https://doi.org/10.1002/9780470758359

Ohannessian, S., Ferguson, C. A., \& Polome, E. C. (1975). Language surveys in developing nations. Papers and reports on sociolinguistic surveys. Arlington, Virginia: Center for Applied Linguistics.

Romaine, S. (1994). Language in Society. An Introduction to Sociolinguistics. Oxford: Oxford University Press.

Schmidt, R. W. (1974). Sociostylistic Variation in Spoken Egyptian Arabic: An Examination of the Concept of Diglossia. PhD thesis. Brown University.

Sidnell, J. (1999). Competence. Journal of Linguistic Anthropology, 9(1-2), 38-41. https://doi.org/10.1525/jlin.1999.9.1-2.39

Taqi, H. (2010). Two Ethnicities Three Generations: Phonological variation and change in Kuwaiti Arabic. $\mathrm{PhD}$ thesis. Newcastle University.

Thomason, S. G. (2001). Language Contact: An Introduction. Edinburgh: Edinburgh University Press \& Georgetown University Press.

Trudgill, P. (1986). Dialects in Contact. Oxford: Blackwell.

Trudgill, P. (1996). Language contact and inherent variability: The absence of hypercorrection in East Anglian present tense forms. In J. Klemola, M. Kytö, \& M. Rissanen (Eds.), Speech Past and Present: Studies in English Dialectology in Memory of Ossi Ihalainen (pp. 412-45). Frankfurt and Main: P. Lang.

Trudgill, P. (2000). Sociolinguistics: An Introduction to Language and Society (4th ed.). England: Penguin Publishing.

Versteegh, K. (1997). The Arabic Language. Edinburgh: Edinburgh University Press.

\section{Copyrights}

Copyright for this article is retained by the author, with first publication rights granted to the journal.

This is an open-access article distributed under the terms and conditions of the Creative Commons Attribution license (http://creativecommons.org/licenses/by/4.0/). 